ingredients most commonly associated with food intolerance (milk, egg, wheat, soya bean, cocoa, BHA and BHT, sulfur dioxide, benzoate, glutamate and azo colours).

\title{
SUGAR, ASPARTAME AND BEHAVIOR
}

The effects of glucose, sucrose, saccharin, and aspartame on aggression and motor activity in 30 boys, ages 2-6 years, were studied at the Child Psychiatry Branch and Laboratory of Developmental Psychology, NIMH, Bethesda, MD. Eighteen boys were recruited or selected as "sugar responders" and 12 male playmates were "non responders". Single doses of sucrose, $1.75 \mathrm{~g} / \mathrm{kg}$; glucose, $1.75 \mathrm{~g} / \mathrm{kg}$; aspartame, $30 \mathrm{mg} / \mathrm{kg}$; or saccharine administered in a randomized, double-blind design produced no significant effect on aggression or on teacher ratings of behavior. Actometer counts for 2 hours after ingestion of aspartame were lower than those following other sweeteners. Parent ratings of activity and aggression after home challenges with sweeteners failed to show differences between substances for either the alleged "responders" or "non responders". Consistent with baseline measures, parents rated responders more hyperactive than playmates who were not believed to be sugar reactive. No parent differentiated between sugar and nonsugar trials. Mean daily sucrose intake and total sugar consumption correlated with duration of aggression against property for the alleged sugar responsive group but acute sugar loading did not increase aggression or activity in preschool children. (Rrnesi MJP et al. Effects of sugar and aspartame on aggression and activity in children. Am J Psychiatry 1987;144:1487-1490).

COMMENT. Conners $\mathrm{CK}$ at the Children's Hospital, Washington, D.C. reports that deleterious effects of sugar on children with attention deficit may be demonstrated if the challenge follows a high carbohydrate breakfast but the effects are blocked or reversed by a protein load. The beneficial and protective effects of a protein diet are correlated with neuroendocrine changes and the prevention of the serotonergic effects of sugar on behavior and attention (personal communication and in Diet and Behavior, Lubbock, Texas Tech Univ Press). Diets low in protein and high in carbohydrates might be expected to cause increases in spontaneous activity, as demonstrated in animal studies, but these effects are not necessarily related to swings in blood sugar concentrations. For recent reviews of the effects of dietary nutrients and deficiencies on brain biochemistry and behavior see Yehuda S. Intern J Neuroscience 1987;35:21-36; and Nutrition Reviews/Supplement May 1986;44:1-250.

\section{PAROXYSMAL DISORDERS}

\section{HEMISPHERECTOMY FOR CHIDDOOD EPIIEPSY}

Seventeen patients treated for hemiplegic epilepsy by hemispherectomy between 1950 and the present day have been followed up at the National Centre for Children with Epilepsy, The Park Hospital for Children, Oxford. The causes of the seizures were associated with perinatal complications in 8 and early febrile status epilepticus, prolonged and unilateral, in 9 . Two of the 17 had congenital abnormalities: Sturge-weber disease in one and a heterotopia found at operation in the other. Habitual seizures began at age 1 to 10 yrs after an interval of relative freedom varying 